\title{
DIE DIENS VAN OUDERLING VANDAG
}

ELKE ouderling kwel hom oor die vraag: Hoe moet ek vandag ouderling wees? Daar is heelwat oor geskrywe. Maar hoe lyk die praktyk van ouderling-wees? Om oor die praktyk te praat en by dic huisbesoek uit te kom, moet 'n mens noodwendig eers ' $n$ paar fondamentvore uitteken. Niks is so teoreties soos goeie praktyk nie. Ten slotte rus ons ouderling-wees op belydenis, d.w.s. op ' $n$ antwoord en gehoorsaam-wees aan die Woord van God.

\section{Die ouderlingediens sit onlosmaaklik vas aan die kerk}

Vandag staan in Afrikaanse Kerkgemeenskappe veral twee beskouinge van die kerk teenoor mekaar:

1.1. Daar is ' $n$ vertikale kerkbeskouing soos by Calvyn e.a. gereformeerdes. Daarvolgens is die kerk God se werk. Die kerk van die Here, wortel in en kom op uit die uitverkiesing en die verbond. God roep en maak 'n kerk as sy volk. Op hierdie ,teorie" rus die eerste vraag van die bevestigingsformulier - Erken $u$ dat $u$ deur die kerk en daarom deur God self geroep is? Hierdie gelowige uitgangspunt gee ' $n$ bepaalde betekenis en rigting aan ouderling-wees. Kortom: Geloof in die kerk van die Here laat ons begin met die besef dat die ouderling ouderling van die Here - of niks moet wees nie.

1.2. Daarteenoor staan die horisontale kerkbegrip. In plaas van om met die kerk van die Here te begin, kry ons die idee van „ons kerk". In plaas van die kerk wat wortel in die wil en verkiesing van God - word hierdie kerk bepaal deur die wil en besluite van kerkrade en sinodes. Hierdie vlak menslike (horisontale) kerkbegrip beskou die ouderling basis as lid van die kerkraad, lid van die bestuur van die genootskap. Hy is die ouderlingamptenaar van die kerk (kerkraad). Sommige ou mense het dit ook so uitgedruk: „Hy het kerkraad geword" of "Hy is kerkraad in daardie wyk". Ons praat vandag deftiger: „Hy is tot die kerkraad verkies”. „Hy is lid van die kerkraad". "Hy is kerkraadslid, sinodelid ens." Kortom, die kerkraad is eerder as en voor die ouderling. Die kerkraad maak ouderlinge en nie meer ouderlinge wat die kerkraad maak nie.

\section{Wat moet ons onder, ,amp" verstaan?}

2.1. Dit het by ons gebruiklik geword om in die kerkreg en in die kerklike lewe by voorkeur van die ,ampsdraers" te praat i.p.v. om te onderskei (soos die kerkorde nog doen) tussen "ouderlinge" en „diakens" en ,predikante”. Moontlik het die genootskaplike idee van die Breë Kerkraad as eintlike kerkregerende liggaam en werklike kerkraad dit veroorsaak. Wie van die Breë Kerkraad as kerkraad uitgaan, sien ouderlinge en diakens as kerkraadslede of ,ampsdraers" en sit eintlik verleë met die verskil tussen die dienste van ouderlinge en diakens. Die woord „amp" word gerieflikheidshalwe in kerkreg-besinning gebruik en laat ook geleidelik die onderskeid in dienste 
ten gunste van die gemeenskaplike aspekte (bv. roeping, verkiesing, bevestiging) verdwyn.

2.2. Die woord ,amp" bring waardigheid sterk na vore. Dit is vroeër selfs verbind aan bepaalde klere (ampsgewaad), sitplekke, voorregte, publieke aansien ens. In Europa en Suid-Afrika het hierdie „waardigheid" swaar geweeg. "Amp" wys op 'n posisie eerder as op watter werk die persoon doen. (Nog erger klink die woord ,ampsdraer" wat die ,persoon" en ,amp" verbind soos 'n mens ,las" en "dier" in die begrip "lasdier" verbind). Sodoende is ,amp" 'n kerklike betrekking, 'n klerikale posisie, soos dié van minister in 'n kabinet, landdros in ' $n$ hof of tesourier in ' $n$ tennisklub. Die bekleder is „draer" van 'n waardigheid en posisie oor en teenoor ander lede van die klub. Dit kan gebeur omdat volgens die teorie van Rousseau die ander lede hulle mag na die ,ampsdraer" in funksie gedelegeer het. Op grond van die posisie of amp sou iemand dan gesag en regte in en oor die gemeente verwerf.

Talle ongelukkige voorbeelde illustreer vandag waar die kerkraad selfs oor middelmatige sake teenoor die gemeente te staan kom - of waar die kerkraad of ,ampsdraers" as die aktiewe werkende deel van die gemeente beskou word wat alles wat in die gemeente moet gebeur, begin, organiseer, beheer en uitvoer. Hoe dikwels is georganiseerde jeug of vroue-aksies in die amp van die gelowige nie gefnuik omdat hulle eers "toestemming" van die kerkraad moes kry nie. Die problematiek rondom die vrou ,in die amp" het ook iets hiervan weg: Ampsdiens is christendiens.

Hierin kan sowel die Roomse idee en rangorde van "geestelikes" teenoor "leke" as die liberaal-demokratiese teenstelling tussen ,bestuur" en "lede" teruggevind word. En hoe graag dink ons mense nie so nie! Volgens hierdie idee word ,kerkraadslede" of ,ampsdraers" belas en opgesaal met alles wat in "die gemeente" (die genootskap of vereniging) moet gebeur. Die "lidmate" is soos leke of klublede die passiewe groep. Dus, as vroue nie mag ,ampsdiens" doen nie, is hulle verontreg omdat hulle nie kan ,werk" nie.

Mens kan die stelling maak: Die begrip „ampsdraer” as noemer vir meer as een diens of bediening kom nergens in die Bybel (veral in die N.T.) voor nie. Gevolglik moet ons die ouderlingskap uit die Bybel en nie uit 'n kerklike ,ampsleer" opbou nie.

2.3. Die gemeenskaplike eienskappe van die dienste in die kerk van die Here: Die Bybel gebruik hoofsaaklik twee woorde vir wat vandag „amp" genoem word. Die eerste is gawe en die tweede bediening (dieselfde woord in ,diaken"). „Gawe" beskryf die karakter van die "amp" van die kant van God. Dit sê wat God met die ,amp" (nie die ,ampsdraer" nie) doen. Die woord „bedienaar" (diakonos) sê hoe die "amp" van die kant van die gemeente lyk; hoe die "gawe" funksioneer as ,diens" in die gemeente. Die ouderling moet dus "gawe" (van God se kant) en "bedienaar" (van die gemeente se kant besien) in die gemeente wees.

Die bediening (ouderlingskap) word daarom altyd in die Bybel in verhouding tot God gesien. Die ouderling is dienaar van God en van Jesus Christus. Die valse ,ampsdraer" gee voor dat hulle van Christus is (2 Kor. $11: 13$ ), maar is dit nie. Dit beteken dat die 
oudcrling moet weet dat hy God in die gemeente van God bedien. God moet deur sy diens in sy eie gemeente regeer (1 Petr. $4: 11$ ); - anders voer dic ouderlinge heerskappy en is hy 'n valse herder wat om eer of gewin 'n ,amp" beklee.

2.2.3. Die bediening van die ouderling is nie deur 'n sinode of mense uitgedink nie. Die Bybel leer dat God ouderlinge as herders in die gemeente gegee en gestel het (Ef. $4: 12$; Hand. $20: 28$; 1 Kor. $12: 28$ ). Christus is die Hoof van sy gemeente (Ef. $1: 22$ ). Daarom is die ouderling nic langs of in die plek van Christus nic. Ons bely dus dat Christus die ouderlinge in diens neem en dat hulle sy werk moet doen. Die ouderling se diens moet dus die hoof-wecs van Christus in sy gemeente uitdruk.

Die ouderling se waarde en diens moet in Christus wortel. Sy diens (nie hy nie) moet Christus by sy gemeente verteenwoordig. Calvyn sê dat die ampsdraer slegs instrument in sy hand is. ' $n$ Instrument hoef niks anders te doen as om hom te onderwerp aan die een wat hom hanteer nie. Op sterkte van Joh. 13 kan mens benadruk: die herder neem nie, hy gee. Hy kan Christus nie verplaas (Rome) nie, want Christus is in sy Woord en Gees deur die bediening van die ouderling self teenwoordig in die gemeente. Die ouderling se diens moet dus nie die kerkraad by die lidmate verteenwoordig nie. Nee, die ouderling moet in sy diens Christus by elke huis en elke lidmaat verteenwoordig. Dan is hy 'n herder, dienskneg, slaaf van Jesus Christus. Hand. $15: 23$ en 28 verbind die gesag van dic ouderlinge in die kerk so regstreeks aan die Heilige Gees. Die werklike teenwoordigheid van God in die Gees sny elke gedagte aan magsdelegasie in die bediening of in die amp af. 2.3. Amp word met die oog op die gemeente bedien: „En hy het gegee sommige... om die heiliges toe te rus vir hulle dienswerk tot opbouing van die liggaam van Christus" (Ef. 4 : 12). Hand. 9 : 31 wys dat die gemeentes vrede gehad het terwyl hulle opgebou is en gewandel het in die vrees van die Here en die vertroosting van die Heilige Gees. Op een plek soos 2 Tim. $3: 17$ sê die Skrif met nadruk dat die bediening geskied sodat die "mens van God (let op die individuele, B.S.) volkome kan wees, vir elke goeie werk volkome toegerus". Die ouderling moet dus onthou dat hy die gelowige individu (2 Tim. $3: 17$ ) maar ook die gelowiges saam (Ef. 4 : 12) moet toerus. Dit is veral die taak van die leer-ouderling. Maar ook die regeer-ouderling moet besig wees om die heil te soek van elke individu en al die individue in gemeenskap wat onder sy sorg verkeer.

Voorop moet die doel gekoester word dat die gemeente moet toeneem in getal en grootte - maar veral ook moet elke lid geestelik groei sodat „die mense... julle goeie werke kan sien en julle Vader wat in die hemel is, verheerlik". Kortom, die dienste (ook die ouderlingdiens) is primêr gegee en gerig met die oog daarop dat elke lid en al die gelowiges saam diens aan God (godsdiens) bring. Die Bybel sê die gemeente is 'n liggaam waarin elke lid sy plek neem (1 Kor. 12). Ook die diens van ouderling is uitsluitend gerig om die liggaam-as-geheel-onder-die-hoof-Christus, en elke-lidin-die-liggaam-van-Christus gesond en altyd beter te laat lewe. 
Kortom, die Bybel vestig die aandag eintlik on die dienswerk van elke man, vrou en kind se Christenwees (,,amp-van-die-gelowige") in die wêreld. Dit is die eintlike en grootste ,ampswerk". Die christene is die eintlike ,ampsdraers". Mens hoef nie eers vroue en kinders of ander mans tot ouderlinge te verkies voordat of sodat hulle kan "dien" nie. Nee, die dienste is gegee (nie met die oog op kerk of kerkorganisasie nie) met die oog op die lewende christene, die mense van God. Op hierdie feit behoort die hele bediening van elke ouderling gerig te wees. Ek sê behoort.

Hoeveel lidmate kry uit die ontmoetinge en gesprekke met predikante en ouderlinge, uit afkondigings, nuusbriewe, oproepe en uitnodigings, klassis- en sinodeverslae eerder die indruk dat hulle daar is ter wille van die „kerkraad" (as liggaam of kollege) of die „kerk" (as sigbare instituut) i.p.v. dat die bediening en bedienaars hulle deurdring met die wete: Christus het hierdie bediening en ouderlinge vir my en met die oog op my self gegee. Hy bou my en ons almal so op om God te dien (godsdiens).

2.4. lemand word persoonlik gegee om 'n diens te lewer. Ek wil ook baie duidelik onderstreep dat die Bybel leer dat God iemand ('n mens) as apostel, predikant, herder of ouderling aan die gemeente gee. Die Here gee nie 'n onpersoonlike abstrakte „amp”, posisie of ouderlingskap nie - die Here gee 'n mens, lemand in 'n diens aan die gemeente. So moet daardie mens en sy werk 'n gawe van die Here aan en in sy gemeente wees. Dit beteken dat iemand wat die naam, status of waardigheid van ouderling (of predikant) dra, maar daardie diens versuim, 'n ontroue of valse ouderling is. Vandag dink ons Westerlinge abstrak oor regering. Ons skryf dit toe aan „die staat", „die regering" en selfs „die kerkraad". In die Bybel is dit egter Dawid as koning, Paulus as apostel en Jakobus as ouderling wat regeer (toesig hou).

Aan die anderkant, al het iemand al die bekwaamhede, opleiding en geloof om predikant of ouderling te wees - maar hy is nie in daardie diens onder 'n roeping van die Here gestel en openlik (vir kerk en wêreld om te weet) in die gemeente daarin bevestig nie, moet hy nog dien maar tog doen hy geen ,amptelike" ouderlingsdiens nie. Elke Christen moet juis as Christen bereid wees om te getuig, te vermaan, te leer (Heid. Kat., Sond. 21).

\section{Die besondere diens van ouderling}

In die Bybel dui (twee woorde die diens aan: ouderling (presbuteros) en opsiener (episkopos, biskop). Die naam „ouderling” het uit die Joodse agtergrond die betekenis van 'n bepaalde waardigheid met die oog op regering verkry. So ken die Skrif apostels, leraars en herders as ouderlinge. Die "oudste" het as ouderling altyd in die O.T. en N.T. met regspraak, regering, toesig hou, gesag te doen gehad. Die taak van die herders of regeer-ouderlinge kom daarom neer op die begrip „opsieners". Hand. 20:28 aan die „ouderlinge”: "Gee dan ag op julleself en op die hele kudde waaroor die Heilige Gees julle as opsieners aangestel het om as herders die gemeente van God te versorg wat Hy deur sy eie bloed verkry het". 
Die bevel om ,ag te gee op julleself en die hele kudde" beteken dat die ouderling sy gedagtes, gees en aandag daaraan moes wy. Hy moes hom dus toe wy aan die ouderling-wees. In die begrip sit daar: om vas te hou aan, om daar by te behoort. Die mees elementêre eienskap van ouderling-wees vra dus nie dat iemand getrou op sy pos in en by die vergaderings en kerkraad sal wees nie. Nee, die vernaamste eis is dat die ouderling homself sal dissiplineer om hom toe te wy aan die broeders en susters wat aan hom toevertrou is. Elke man, vrou, jongman en dogter, elke kind moet weet hulle leef in die ouderling se gedagtes - Hy gee aan hulle aandag hier en nou en voor die troon van die Here in sy gebede.

Dit beteken dat die ouderling veral sy huisbesoek moet inrig om by elkeen in die wyk tuis te bring dat hy hulle vashou, by en aan hulle behoort, met hulle besig is kragtens 'n opdrag van Christus, want so is Christus voortdurend met hulle besig.

Die opdrag om as herders die gemeente van God te versorg beteken kortweg om 'n skaapwagter vir elke lid en almal saam te wees. Maar in die Woord sit ook die gedagtes van op te pas, te versorg, te ondersoek, op te beur, te vertroos, te lei - en so ook te voed. Die ouderling moet sy huisbesoek dus so inrig dat hy werklik herder sal wees. Dit kan hy nie uit homself wees nie. Hy moet Christus (Ek is die goeie Herder, Ps. 23 : 1; Joh. 10; Die Herder en Opsiener van julle lewes, 1 Petr. 2 : 25) aan elkeen en almal saam onder sy sorg bring. Beter gesê: Hy moet so optree dat Christus self deur sy diens herder van die mense is.

Uit 1 Tim. $3: 1-7$ en Tit. $1: 6$ e.v. is duidelik dat die bediening van ouderling verder inhou: aan-hoof-staan, onder tug hou en versorg. Hulle moet dus die goeie gang van sake in die gemeente bepaal. Die ouderling moet kan onderwys gee, voorbeeld gee en veral die gesonde leer kan verdedig teen teensprekers.

Die diens en regering van die ouderlinge is dus geensins administratief van aard nie. Hulle diens is geestelik. Hulle moet met die stok van die Woord die kudde lei. Die ouderling het dus die leiding van die Gees self onophoudelik nodig. Die Here moet hom die gawes gee sodat die Woord deur sy diens kan deurvloei in die gemeente en in elke lid daarvan. Dan verdien hulle tereg die naam van „voorgangers".

\section{Die slaggate vir die diens vandag}

Wanneer die ouderling die huis instap en dink: „Ek is Jan Pieterse en wat gaan Neels Kok nou van my huisbesoekery dink?" is hy so horinsontaal gemotiveer dat hy die besoek net so goed in belang van 'n politieke party kan bring. Wanneer hy die besoek aflê omdat die kerkraad dit aan hom opgedra en hy verslag moet doen, is hy ' $n$ blote amptenaar van die kerkraad en geen herder van Christus nie want die kerkraad is nou eenmaal nie Christus nie. Hoe weinig ouderlinge dien hulle beskeie aan in die naam van Christus! Gewoonlik sê hulle maar: „Die kerkraad wil graag weet hoe staan dit met die kerkbesoek, bydrae of katkisasie". Baie ouderlingwerk verstik in hierdie horisontale en formele organisasieslaggat. Slegs wanneer hy die Bybel gryp en 'n gebed doen sodat hy verder 
kan gaan, lyk hy enigsins na 'n ouderling. So 'n „ouderling” kruip agter die kerkraad weg. "Die kerkraad het aan my opgedra... Die kerkraad wil weet..." - in plaas van om in die naam van Christus uit te stap en te praat oor Christen-wees eerder as oor lidmaat-wees. Lg. benadering verabsoluteer die kerk as instituut en organisasie en maak dit 'n diensobjek op homself.

Wanneer die ouderling self te skaam is om te laat blyk dat hy Christus ken en probeer op neutrale grond bly, is hy inderwaarheid geen ouderling nie. Ewenso die man wat nou juis 'n "geestelike gesprek" wil afdwing en forseer oor 'n tema en op 'n vlak waarop hy hom alleen ingegrawe het of waarvan hy dikwels maar 'n halwe of verwronge begrip het, kom so verwaand, aanmatigend, afstotend "waardig" voor, dat Christus nie in sy diens gevind word nie.

Die opgeblase man wat uit die hoogte daar kom sit en die mense laat voel hulle het besoek van 'n kerklike skutmeester of balju, het al menige gelowiges laat struikel. Hulle laat bloedspore deur gemeentes en wyke agter. Val dit nie op hoe weinig mense op grond van hulle ervaring in die verlede nog werklik behoefte aan 'n gesprek met 'n ouderling of dominee het nie? Lê die oorsaak daarvan nie in onnadenkende en ongemaklike egosentriese besoeke waarin besoekers heel tyd self aan die woord bly, presies vir die "lidmaat" wil sê hoe dit moet, oor homself en sy familie se siektes praat, oor hoe min tyd hy as ouderling het en hoe lastig die huisbesoek inpas - in plaas van om werklik belang te stel en op te gaan in die ,kudde" of die mens voor hom?

\section{5. 'n Positiewe verkenning vandag}

5.1. Motivering: Dit is essensieel dat die ouderling vandag begin deur op homself ag te gee (Hand. $20: 28$ ). Hy moet homself motiveer. Motivering is daardie innerlike gerigtheid op 'n bepaalde doel - 'n onmiddellike sowel as 'n verwyderde doel. Die verwyderde doel moet altyd die toerusting van die heiliges en die opbouing van die gemeente van die Here Jesus Christus op die oog hê. By die onmiddellike doel kan egter gepoog word om die gesin meer te laat deelneem; of hierdie doel kan wees om geestelike hindernisse weg te ruim of om bepaalde probleme en tuggevalle te hanteer. Die doel moet kontak met die gesin en elke gelowige wees sodat daar 'n „ontmoeting" op huisbesoek plaasvind.

Die onmiddellike doel moet egter baie duidelik nagestreef word in lyn met die uiteindelike doel. Die ouderling moet vandag op huisbesoek veel meer as in die verlede daarteen waak om die institusionele, die „lidmaat-van-die-kerk-wees", sonder die band met essensiële christen-wees, te benadruk. Sy poging om nadruk op die kerk te lê, kan juis die kerk skade doen wanneer die "lidmaat" die indruk kry dat sy band met die kerk nie regstreeks met sy christen-wees verband hou nie. Dit is geen motivering om net te beweer dat 'n christen aan die kerk moet behoort nie.

5.2. Selfvoorbereiding: Onmiddellik nadat die ouderling sy eie motivering in orde het, moet hy homself voorberei. Hier moet gebed die eerste en vernaamste plek neem. Die verloop van 'n besoek in 'n 
huis hang af van die voorbereiding van die ouderling in sy binnekamer. Saam met gebed gaan die oordenking van of aantekeninge oor Skrifwoorde wat op die onmiddellike en verwyderde doel met huisbesoek gerig is.

5.3. Intrede: By die huis of persoon moet die ouderling sy posisie t.o.v. Christus en die lidmaat baie eerlik en opreg aankondig. Laat die lidmaat verstaan dat die ouderling maar net 'n gawe van Christus deur middel van diens aan die lidmaat wil wees. Soos 'n ambassadeur of gesant eers sy kredensiepapiere moet oorhandig, so moet die ouderling by huisbesoek ook sy kredensiebrief oorhandig. Wanneer die verdere verloop bewaarheid dat in wese Christus besoek doen deur sy Woord en Gees in die diens van die ouderling, word die onsigbare kerk gebou, die liggaam van die Here.

5.4. Metode van vrae: Natuurlike en goedgemikte persoonlike vrae is die beste middel om ' $n$ huisbesoek te ontplooi. Dit skep vertroue wat die lidmate laat oopmaak. Dit laat hulle immers praat. Wisselende belangstellende vrae openbaar aandag vir elke lid - selfs elke kind van die gesin. Wanneer die ouderling onraad ruik, moet hy goed dink voordat hy te ver deurpraat. Hier moet liefde en bedagsaamheid hom beweeg om op te offer en weer op besoek te kom, liewer as om een lid van 'n gesin ten aanhore van 'n ander persoonlik te vermaan. Wanneer 'n jongmens voor sy ouers of een ouer voor die ander of kinders aangespreek word, kan ' $n$ onherroeplike skok en verwydering die gevolg wees. Matt. $18: 15$ geld ook hier. Bestraf altyd onder vier oë. Die offer om weer en "spesiaal" te kom sal inteendeel vertroue inboesem en van liefde getuig.

5.5. 'n Ouderling moet nooit geforseerde „geestelike" gesprekke aanknoop nie. In dergelike gevalle kan liewer oor allerlei alledaagse sake en selfs rugby gesels word. Selfs in so ' $n$ alledaagse ontmoeting kan die ouderling diagnoseer, oplet wanneer en waaroor raak die persoon vrymoedig, agterdogtig, skugter, ens. Sonder waardering en begrip vir die leefwêreld van 'n bepaalde mens, sal geen ouderling "geestelik" indring en daardie mens "bedien" nie. Die mens sal eerder in stilte ly onder die "klappe" op huisbesoek en daarna eensaam in die Bybel en gebed na die Goeie Herder soek of hy sal hom afsluit en verder onverskillig teenoor die tipe bediening raak.

5.6. 'n Ouderling moet nooit die indruk gee dat hy haastig is nie, of nog baie besoeke moet aflê nie. Wat het die lidmaat daarmee te doen? Indien iemand dan vir die lidmaat geen of te min tyd het nie, so sal hy redeneer, moet die persoon liewers nie by hom aankom nie.

5.7. Waar die herdersamp in sy wese met versorg en tug te doen het - moet onthou word dat tug in sy wese opvoed beteken. Die ouderling moet daarom elke lidmaat en gesin positief benader. Gaan altyd uit van wat waardeer kan word en nie van wat verkeerd is nie Aanmoediging is belangriker as teregwys. Wanneer vermaan word, moet die ouderling weet wat hy wil sê en hoe hy dit moet meedeel. 
Hy moet homself in die lidmaat se plek verplaas, dan sal die liefde lei. Die ouderling moet self 'n voorbeeld van die Christus met 'n linnedoek wees (Fil. $2: 3$ en 4). Wie die ander hoër ag as homself en na die ander se belange omsien, bedien Christus ook in die tugoefening.

5.8. Die goeie ouderling kan eintlik maar vergeet dat hy op 'n kerkraad dien of verslag moet doen. 'n Ouderling wat die liefde van Christus bedien, moet slegs 'n saak wat hy (en moontlik reeds saam met 'n naburige ouderling) nie meer kan hanteer nie, of 'n openbare sonde, aan die kerkraad rapporteer. Net soos wat 'n kerkraad nie alles wat hy doen in die Klassis vertel nie - net so sal die bewoë ouderling van Christus nie alles wat hy ontmoet, gehoor of gedoen het in die kerkraad vertel nie. Christus bedien hom immers volgens die Skrif primêr van ouderlinge (meervoud) en daar verloop die eerste en vernaamste fase van die opsig (opsien) oor die kerk. Hulle kom eers sekondêr saam in 'n kerkraad en gevolglik gaan dit daar net oor wat hulle in die bediening nie kon afhandel nie.

Ouderlinge moet as ouderlinge Christus verteenwoordig sodat Hy met sy Woord en Gees regeer. Te veel het kerkrade die regeerplek van Christus in sy kerk geneem en het kerkrade die ouderlinge van Christus hulle ouderlinge gemaak.

(Gelewer voor ouderlinge in Klassis Krugersdorp) 